\title{
Efficacy and safety of the dipeptidyl peptidase- 4 inhibitor sitagliptin as monotherapy in patients with type 2 diabetes mellitus
}

\author{
I. Raz • M. Hanefeld $\cdot$ L. Xu • C. Caria • \\ D. Williams-Herman $\cdot$ H. Khatami • \\ Sitagliptin Study 023 Group
}

Received: 31 March 2006 / Accepted: 11 July 2006 / Published online: 26 September 2006

(C) Springer-Verlag 2006

\begin{abstract}
Aims/hypothesis The aim of this study was to assess the efficacy and safety of sitagliptin (MK-0431) as monotherapy in patients with type 2 diabetes mellitus and inadequate glycaemic control $\left(\mathrm{HbA}_{1 \mathrm{c}} \geq 7 \%\right.$ and $\left.\leq 10 \%\right)$ on exercise and diet.

Methods A total of 521 patients aged 27-76 years with a mean baseline $\mathrm{HbA}_{1 \mathrm{c}}$ of $8.1 \%$ were randomised in a $1: 2: 2$ ratio to treatment with placebo, sitagliptin $100 \mathrm{mg}$ once daily, or sitagliptin $200 \mathrm{mg}$ once daily, for 18 weeks. The efficacy analysis was based on an all-patients-treated population using an analysis of covariance, excluding data obtained after glycaemic rescue.

Results After 18 weeks, $\mathrm{HbA}_{1 \mathrm{c}}$ was significantly reduced with sitagliptin $100 \mathrm{mg}$ and $200 \mathrm{mg}$ compared with placebo (placebo-subtracted $\mathrm{HbA}_{1 \mathrm{c}}$ reduction: $-0.60 \%$ and $-0.48 \%$, respectively). Sitagliptin also significantly decreased fasting plasma glucose relative to placebo. Patients with higher
\end{abstract}

Electronic supplementary material Supplementary material is available in the online version of this article at http://dx.doi.org/ $10.1007 / \mathrm{s} 00125-006-0416-\mathrm{Z}$ and is accessible to authorised users.

For the Sitagliptin Study 023 Group see electronic supplementary material for list of study investigators.

\footnotetext{
I. Raz

Diabetes Research Center, Hadassah University Hospital,

Jerusalem, Israel

M. Hanefeld

Centre for Clinical Studies, Dresden Technical University,

Dresden, Germany

L. Xu $\cdot$ C. Caria $\cdot$ D. Williams-Herman $\cdot H$. Khatami $(\square)$

Merck Research Laboratories,

126 East Lincoln Avenue, RY34-A256,

Rahway, NJ 07065-0900, USA

e-mail: hootan_khatami@merck.com
}

baseline $\mathrm{HbA}_{1 \mathrm{c}}(\geq 9 \%)$ experienced greater placebo-subtracted $\mathrm{HbA}_{1 \mathrm{c}}$ reductions with sitagliptin $(-1.20 \%$ for 100 $\mathrm{mg}$ and $-1.04 \%$ for $200 \mathrm{mg}$ ) than those with $\mathrm{HbA}_{1 \mathrm{c}}<8 \%$ $(-0.44 \%$ and $-0.33 \%$, respectively) or $\geq 8 \%$ to $8.9 \%$ ( $-0.61 \%$ and $-0.39 \%$, respectively). Homeostasis model assessment beta cell function index and fasting proinsulin: insulin ratio, markers of insulin secretion and beta cell function, were significantly improved with sitagliptin. The incidence of hypoglycaemia and gastrointestinal adverse experiences was not significantly different between sitagliptin and placebo. Sitagliptin had a neutral effect on body weight.

Conclusions/interpretation Sitagliptin significantly improved glycaemic control and was well tolerated in patients with type 2 diabetes mellitus who had inadequate glycaemic control on exercise and diet.

Keywords Diabetes - Dipeptidyl peptidase-4 - DPP-4 · Glucagon-like peptides · Incretins · MK-0431 - Sitagliptin 


\section{Introduction}

Sitagliptin (MK-0431) is an orally active, potent and selective dipeptidyl peptidase-4 (DPP-4) inhibitor in development for the treatment of patients with type 2 diabetes mellitus [1]. Sitagliptin acts through increasing active incretin hormone concentrations. Following ingestion of a meal, incretins, including glucagon-like peptide-1 (GLP-1) and glucose-dependent insulinotrophic polypeptide (GIP), attenuate the post-meal rise in glucose concentration and reduce fasting glucose concentrations [2]. Both GLP-1 and GIP are rapidly inactivated by the enzyme DPP-4 $[3,4]$. In patients with type 2 diabetes, treatment with single doses of sitagliptin provided sustained 24-h inhibition of DPP-4 enzyme activity and increased active GLP-1 and GIP concentrations, leading to increases in insulin and C-peptide, reductions in glucagons and improvements in oral glucose tolerance [5]. Administration of the GLP-1 analogue, exenatide, and the DPP-4 inhibitors, NVP DPP728, P32/ 98 , vildagliptin, and des-fluoro sitagliptin, in diabetic animal models has been shown to lead to improvements in beta cell function and/or neogenesis [6-10]. Improvements in beta cell function have also been observed with exenatide and vildagliptin in patients with type 2 diabetes [11-14]. In 12week dose-range-finding studies (25-100 $\mathrm{mg}$ daily) in patients with type 2 diabetes mellitus, sitagliptin $100 \mathrm{mg}$ was the most effective dose across various glycaemic parameters $[15,16]$. The current study assessed the safety and efficacy of once-daily sitagliptin $100 \mathrm{mg}$ and $200 \mathrm{mg}$ in patients with type 2 diabetes mellitus with inadequate glycaemic control on diet and exercise.

\section{Subjects and methods}

\section{Subjects}

Men and women with type 2 diabetes mellitus, 18-75 years of age, were recruited. Patients not currently on oral antihyperglycaemic agent (OHA) therapy and patients on OHA monotherapy (or dual oral combination therapy in low doses) who could be taken off their OHA(s) during the run-in period, were eligible. Key exclusion criteria included type 1 diabetes, insulin therapy, significant hepatic or renal disease, hepatic transaminase or creatine phosphokinase (CK) levels $\geq 2$ times the upper limit of normal, fasting plasma glucose $(\mathrm{FPG})>15 \mathrm{mmol} / \mathrm{l}(270 \mathrm{mg} / \mathrm{dl})$ and BMI $<20 \mathrm{~kg} / \mathrm{m}^{2}$ or $>43 \mathrm{~kg} / \mathrm{m}^{2}$. Patients received counselling on a diet consistent with American Diabetes Association recommendations at study entry.

The study protocol was reviewed and approved by the appropriate ethics committees and authorities. All patients provided written informed consent. The study was performed in accordance with the Declaration of Helsinki.

\section{Study design}

This was a multinational, randomised, double-blind, placebocontrolled, parallel-group study. The current report presents the initial 18-week, placebo-controlled study period; patients completing this period were eligible to enter an active-controlled, double-blind period, which was ongoing at the time of this report and which will be the subject of a later publication. Patients who entered the study on OHA therapy had the agent(s) discontinued and underwent a wash-off and diet and exercise run-in period of up to 12 weeks, based upon their prior therapy and $\mathrm{HbA}_{1 \mathrm{c}}$ at study entry. Patients not on an OHA (for $\geq 8$ weeks prior to screening visit) at study entry who met randomisation $\mathrm{HbA}_{1 \mathrm{c}}$ criteria directly entered the 2-week, single-blind placebo run-in period. Patients whose $\mathrm{HbA}_{1 \mathrm{c}}$ was $\geq 7 \%$ and $\leq 10 \%$ and who had adequate compliance $(\geq 75 \%)$ during the single-blind run-in period were eligible to be randomised in a 1:2:2 ratio to receive placebo, sitagliptin $100 \mathrm{mg}$ or sitagliptin $200 \mathrm{mg}$ once daily for 18 weeks. During the double-blind treatment period, patients not meeting specific glycaemic limits were provided rescue therapy (metformin). The glycaemic rescue criteria were as follows: $\mathrm{FPG}>15.0 \mathrm{mmol} / 1(270 \mathrm{mg} / \mathrm{dl})$ between randomisation (day 1) and the post-randomisation visit at week 6; FPG $>13.3 \mathrm{mmol} / 1(240 \mathrm{mg} / \mathrm{dl})$ after week 6 through to week 12; or FPG $>11.1 \mathrm{mmol} / \mathrm{l}(200 \mathrm{mg} / \mathrm{dl})$ after week 12 through to week 18 . Patients on rescue therapy remained in the study to provide additional safety experience with sitagliptin treatment, but only data collected prior to rescue were included in the efficacy analyses (see Statistical analyses section below).

\section{Study endpoints}

Efficacy assessments The primary endpoint was $\mathrm{HbA}_{1 \mathrm{c}}$; key secondary endpoints included FPG, insulin and proinsulin and lipids. Insulin was assayed using the Elecsys Insulin system (reportable range: $1.2-6,000 \mathrm{pmol} / \mathrm{l}$; average CV of controls: 5.5\%) [17]. Proinsulin was assayed using the Mercodia Pro-insulin EIA assay (reportable range: 1-132 pmol/l; average CV of controls: 5.7\%) [18]. A subset of patients underwent a meal tolerance test at baseline (day $1 /$ randomisation) and at week 18 . The meal for this test consisted of a nutrition bar and drink (approximately 460 $\mathrm{kcal} ; 75 \mathrm{~g}$ of carbohydrate, $9 \mathrm{~g}$ of fat and $18 \mathrm{~g}$ of protein). Key postprandial endpoints included 2-h post-meal glucose, insulin and C-peptide, and 3-h post-meal glucose, insulin, C-peptide, and insulin and glucose AUCs. 
Safety assessments Data for adverse experiences, physical examinations, vital signs, ECGs, and body weight were collected throughout the study. All adverse experiences were rated by the investigators for relationship to study treatment according to the following categories: definitely not, probably not, possibly, probably or definitely. Adverse experiences assessed as possibly, probably or definitely related were grouped as drug-related. Laboratory safety was collected during the study and included blood chemistry (including alanine aminotransferase, aspartate aminotransferase, total bilirubin, alkaline phosphatase, $\mathrm{CK}$ and creatinine), haematology and urinalysis.

\section{Statistical analyses}

All efficacy analyses were based on the all-patientstreated (APT) cohort that consisted of randomised patients who had at least one dose of study treatment and both a baseline and at least one post-baseline measurement. Only efficacy data collected prior to rescue were included in the efficacy analysis. An analysis of covariance model was used to compare the treatment groups for the continuous efficacy parameters, focusing on change from baseline (day $1 /$ randomisation) at week 18. The model included terms for baseline values and the presence/absence of prior OHA therapy. Missing data were handled using the last observation carried forward method. The primary hypothesis regarding a significant benefit of sitagliptin compared with placebo in decreasing $\mathrm{HbA}_{1 \mathrm{c}}$ was assessed using a closed testing procedure. First, the statistical significance of the difference in the leastsquares (LS) means of sitagliptin $100 \mathrm{mg}$ vs placebo was determined, and, if significant ( $p<0.05$, two-sided), the same comparison was made between sitagliptin $200 \mathrm{mg}$ and placebo. Subgroup analyses of $\mathrm{HbA}_{1 \mathrm{c}}$ effect by prespecified baseline factors were also performed. The proportion of patients requiring metformin rescue therapy was determined for each treatment group.

Safety and tolerability were assessed by reviewing adverse experiences, laboratory parameters, body weight, vital signs and ECGs. Continuous safety endpoints were analysed via analysis of covariance as described for the efficacy parameters. The analysis of safety parameters used a multi-tiered, all-patients-as-treated approach. For the clinical adverse experiences of hypoglycaemia, and prespecified, selected gastrointestinal adverse experiences of nausea, vomiting, diarrhoea and abdominal pain, and for change from baseline in body weight, between-group differences were tested for statistical significance. For other adverse experiences and predefined limits of change in laboratory variables, the between-group differences and associated 95\% CIs were provided. The analyses of body weight and gastrointestinal adverse experiences excluded data obtained after patients received rescue therapy.

\section{Results}

Disposition, baseline demographics and disease characteristics The overall disposition of patients during the placebocontrolled period is shown in Electronic supplementary material (ESM) Fig. 1. Of the 1,387 patients screened, 866 did not meet inclusion or met exclusion criteria. Of the 521 randomised patients, the treatment groups were generally well balanced for baseline demographics and glycaemic efficacy variables (ESM Table 1). For the entire study population, the average duration of diabetes was 4.5 years, average baseline $\mathrm{HbA}_{1 \mathrm{c}}$ was $8.1 \%$ (range: $6.2-10.5 \%$, with $51 \%$ of patients having baseline $\mathrm{HbA}_{1 \mathrm{c}}<8 \%$ ), and the average baseline FPG was $10.1 \mathrm{mmol} / 1$ (182.2 $\mathrm{mg} / \mathrm{dl})$. A total of $463(88.9 \%)$ patients completed 18 weeks of treatment, and $495(95.0 \%)$ patients were included in the APT analysis. Of the 26 randomised patients excluded from the APT analysis, five had no baseline data and 21 had no on-treatment data. There were no clinically meaningful differences among treatment groups in the percentage of patients who completed or discontinued from the study. The proportions of patients requiring metformin rescue therapy during the 18 -week study were $8.8 \%(n=18), 11.7 \%(n=24)$ and $17.3 \%(n=19)$ for the sitagliptin $100 \mathrm{mg}$, sitagliptin 200 $\mathrm{mg}$ and placebo groups, respectively.

Efficacy At week 18, treatment with sitagliptin at both the $100 \mathrm{mg}$ and $200 \mathrm{mg}$ doses led to a significant $(p<0.001)$ reduction from baseline in $\mathrm{HbA}_{1 \mathrm{c}}$ compared with placebo (Table 1). Relative to placebo, $\mathrm{HbA}_{1 \mathrm{c}}$ was reduced by $-0.60 \%(95 \%$ CI -0.82 to -0.39$)$ with sitagliptin $100 \mathrm{mg}$ and by $-0.48 \%(-0.70$ to -0.26$)$ with $200 \mathrm{mg}$. After the nadir was reached at week 12 , the mean change from baseline over time in $\mathrm{HbA}_{1 \mathrm{c}}$ rose slightly in the sitagliptin $200 \mathrm{mg}$ and placebo groups, while the mean change from baseline in $\mathrm{HbA}_{1 \mathrm{c}}$ appeared stable after week 12 in the sitagliptin $100 \mathrm{mg}$ group (Fig. 1).

Sitagliptin, at both doses studied, led to a significantly $(p \leq 0.001)$ higher proportion (35.8\% with $100 \mathrm{mg}$ and $28.6 \%$ with $200 \mathrm{mg}$ ) of patients achieving an $\mathrm{HbA}_{1 \mathrm{c}}<7 \%$ at week 18 compared with placebo (15.5\%).

In general, the $\mathrm{HbA}_{1 \mathrm{c}}$-lowering effects of sitagliptin 100 $\mathrm{mg}$ and $200 \mathrm{mg}$ at week 18 were consistent among subgroups defined by sex, age, race, baseline BMI, baseline homeostasis model assessment insulin resistance index (HOMA-IR), baseline homeostasis model assessment beta cell function index (HOMA- $\beta$ ), prior use of OHAs, and baseline metabolic syndrome status. Patients with a baseline duration of diabetes at or below the median 
( $\leq 3.0$ years) had a greater $\mathrm{HbA}_{1 \mathrm{c}}$ reduction with sitagliptin (placebo-subtracted LS mean [95\% CI] $\mathrm{HbA}_{1 \mathrm{c}}$ reductions at week 18 for $100 \mathrm{mg}$ and $200 \mathrm{mg}$ were $-0.90 \%$ [-1.21 to -0.60$]$ and $-0.70 \%$ [ -1.00 to -0.39$]$, respectively) than those with a baseline duration of diabetes $>3.0$ years ( $-0.28 \%$ [ -0.59 to 0.20$]$ and $-0.28 \%$ [ -0.58 to 0.03$]$ for the sitagliptin $100 \mathrm{mg}$ and $200 \mathrm{mg}$ groups, respectively; $p=0.019$ for treatment-by-subgroup interaction).

Patients with higher baseline $\mathrm{HbA}_{1 \mathrm{c}}(\geq 9 \%)$ experienced numerically greater mean placebo-subtracted reductions in $\mathrm{HbA}_{1 \mathrm{c}}$ at week 18 with sitagliptin $(-1.20 \%$ for $100 \mathrm{mg}$, $-1.04 \%$ for $200 \mathrm{mg}$ ) than those with baseline $\mathrm{HbA}_{1 \mathrm{c}}<8 \%$ $(-0.44 \%$ for $100 \mathrm{mg},-0.33 \%$ for $200 \mathrm{mg}$ ) or those with baseline $\mathrm{HbA}_{1 \mathrm{c}} 8-8.9 \%$ ( $-0.61 \%$ for $100 \mathrm{mg},-0.39 \%$ for $200 \mathrm{mg}$ ); however, the treatment-by-subgroup interaction was not significant $(p=0.087)$.
Sitagliptin treatment also led to significant $(p<0.001)$ reductions at week 18 in FPG compared with placebo, with the FPG-lowering effect showing persistence over the 18 weeks of treatment (Table 1; Fig. 1).

The proinsulin:insulin ratio was significantly reduced with sitagliptin $100 \mathrm{mg}$, and HOMA- $\beta$ was significantly improved with both sitagliptin doses, compared with placebo (Table 1). There were no significant treatment effects of sitagliptin on fasting insulin or proinsulin (Table 1), or on HOMA-IR, quantitative insulin sensitivity check index or lipid parameters examined (data not shown).

In the subset of patients $(n=150)$ who underwent a meal tolerance test, treatment with sitagliptin at both doses at week 18 led to a significant decrease relative to placebo in 2-h post-meal glucose and 3-h post-meal glucose AUC, and significant increases in $2-\mathrm{h}$ post-meal C-peptide, 3-h post-

Table $1 \mathrm{HbA}_{1 \mathrm{c}}$ and fasting and postprandial glycaemic parameters

\begin{tabular}{|c|c|c|c|c|c|}
\hline & $n$ & $\begin{array}{l}\text { Week } 0 \text {, } \\
\text { mean }(\mathrm{SD})\end{array}$ & $\begin{array}{l}\text { Week } 18 \\
\text { mean }(\mathrm{SD})\end{array}$ & $\begin{array}{l}\text { LS change from week } 0 \\
\text { at week } 18, \text { mean }(95 \% \mathrm{CI})\end{array}$ & $\begin{array}{l}\text { Placebo-subtracted LS change from } \\
\text { week } 0 \text { at week } 18 \text {, mean }(95 \% \mathrm{CI})\end{array}$ \\
\hline \multicolumn{6}{|l|}{$\mathrm{HbA}_{1 \mathrm{c}}(\%)$} \\
\hline Placebo & 103 & $8.05(0.90)$ & $8.21(1.35)$ & $0.12(-0.05$ to 0.30$)$ & \\
\hline Sitagliptin 100 mg q.d. & 193 & $8.04(0.82)$ & $7.58(1.15)$ & $-0.48(-0.61$ to -0.35$)$ & $-0.60(-0.82 \text { to }-0.39)^{* * *}$ \\
\hline Sitagliptin 200 mg q.d. & 199 & $8.14(0.91)$ & $7.81(1.31)$ & $-0.36(-0.48$ to -0.23$)$ & $-0.48(-0.70 \text { to }-0.26)^{* * *}$ \\
\hline \multicolumn{6}{|l|}{ Fasting glycaemic parameters } \\
\hline Placebo & 107 & $10.2(2.7)$ & $10.6(3.3)$ & $0.4(-0.1$ to 0.9$)$ & \\
\hline Sitagliptin 100 mg q.d. & 201 & $10.0(2.4)$ & $9.3(3.0)$ & $-0.7(-1.1$ to -0.4$)$ & $-1.1(-1.7 \text { to }-0.5)^{* * *}$ \\
\hline Sitagliptin 200 mg q.d. & 202 & $10.2(2.5)$ & $9.6(3.2)$ & $-0.6(-0.9$ to -0.2$)$ & $-0.9(-1.5 \text { to }-0.3)^{* *}$ \\
\hline \multicolumn{6}{|l|}{ Fasting insulin (pmol/1) } \\
\hline Placebo & 81 & $101.4(72.0)$ & $108.0(103.2)$ & $7.2(-7.2$ to 21.0$)$ & \\
\hline Sitagliptin 100 mg q.d. & 168 & $86.4(50.4)$ & $90.6(58.8)$ & $4.2(-5.4$ to 13.8$)$ & $-2.4(-19.8$ to 14.4$)$ \\
\hline Sitagliptin 200 mg q.d. & 173 & $94.8(73.8)$ & $97.8(105.6)$ & $3.6(-6.0$ to 13.2$)$ & $-3.6(-20.4$ to 13.2$)$ \\
\hline \multicolumn{6}{|l|}{ Fasting proinsulin $(\mathrm{pmol} / \mathrm{l})$} \\
\hline Placebo & 77 & $42.3(35.7)$ & $44.2(45.8)$ & $2.9(-2.5$ to 8.2$)$ & \\
\hline Sitagliptin 100 mg q.d. & 167 & $34.6(28.1)$ & $32.1(31.6)$ & $-2.9(-6.5$ to 0.8$)$ & $-5.7(-12.2$ to 0.8$)$ \\
\hline Sitagliptin 200 mg q.d. & 168 & $36.6(32.6)$ & $34.5(34.2)$ & $2.0(-5.7$ to 1.6$)$ & $-4.9(-11.4$ to 1.6$)$ \\
\hline \multicolumn{6}{|l|}{ Proinsulin:insulin ratio } \\
\hline Placebo & 76 & $0.43(0.23)$ & $0.50(0.69)$ & $0.07(-0.02$ to 0.16$)$ & \\
\hline Sitagliptin 100 mg q.d. & 162 & $0.42(0.21)$ & $0.37(0.30)$ & $-0.05(-0.11$ to 0.01$)$ & $-0.12(-0.23 \text { to }-0.01)^{*}$ \\
\hline Sitagliptin 200 mg q.d. & 166 & $0.42(0.22)$ & $0.40(0.32)$ & $-0.02(-0.08$ to 0.04$)$ & $-0.09(-0.20$ to 0.12$)$ \\
\hline \multicolumn{6}{|l|}{ HOMA- $\beta$} \\
\hline Placebo & 80 & $67.9(56.6)$ & $69.0(63.9)$ & $1.0(-8.0$ to 10.0$)$ & \\
\hline Sitagliptin 100 mg q.d. & 168 & $53.3(40.5)$ & $65.4(45.5)$ & $12.1(6.0$ to 18.3$)$ & $11.2(0.3 \text { to } 22.0)^{*}$ \\
\hline Sitagliptin $200 \mathrm{mg}$ q.d. & 171 & $56.4(58.8)$ & $69.5(82.2)$ & $13.0(6.9$ to 19.2$)$ & $12.0(1.2 \text { to } 22.9)^{*}$ \\
\hline \multicolumn{6}{|c|}{ Postprandial glycaemic parameters ${ }^{\mathrm{a}}$} \\
\hline \multicolumn{6}{|c|}{ 2-h post-meal glucose $(\mathrm{mmol} / \mathrm{l})$} \\
\hline Placebo & 27 & $14.7(3.7)$ & $15.1(4.9)$ & $0.3(-1.1$ to 1.6$)$ & \\
\hline Sitagliptin 100 mg q.d. & 62 & $14.6(4.3)$ & $12.5(4.4)$ & $-2.3(-3.2$ to -1.4$)$ & $-2.6(-4.2 \text { to }-1.0)^{* *}$ \\
\hline Sitagliptin 200 mg q.d. & 61 & $15.5(4.2)$ & $12.7(4.4)$ & $-2.7(-3.6$ to -1.8$)$ & $-2.9(-4.6 \text { to }-1.3)^{* * *}$ \\
\hline \multicolumn{6}{|c|}{ 2-h post-meal insulin $(\mathrm{pmol} / \mathrm{l})$} \\
\hline Placebo & 26 & $442.8(484.2)$ & $368.4(426.6)$ & $-43.8(-118.2$ to 30.6$)$ & \\
\hline Sitagliptin 100 mg q.d. & 57 & $342.0(263.4)$ & $364.2(298.2)$ & $27(-22.8$ to 76.8$)$ & $70.8(-16.2$ to 158.4$)$ \\
\hline Sitagliptin 200 mg q.d. & 59 & $306.0(176.4)$ & $312.0(193.2)$ & $-0.6(-48.0$ to 47.4$)$ & $43.8(-44.4$ to 131.4$)$ \\
\hline
\end{tabular}


Table 1 (continued)

\begin{tabular}{|c|c|c|c|c|c|}
\hline & $n$ & $\begin{array}{l}\text { Week } 0 \\
\text { mean }(\mathrm{SD})\end{array}$ & $\begin{array}{l}\text { Week } 18 \\
\text { mean }(\mathrm{SD})\end{array}$ & $\begin{array}{l}\text { LS change from week } 0 \\
\text { at week } 18, \text { mean }(95 \% \mathrm{CI})\end{array}$ & $\begin{array}{l}\text { Placebo-subtracted LS change from } \\
\text { week } 0 \text { at week } 18 \text {, mean }(95 \% \mathrm{CI})\end{array}$ \\
\hline \multicolumn{6}{|c|}{ 2-h post-meal C-peptide (nmol/l) } \\
\hline Placebo & 27 & $2.5(0.9)$ & $2.3(1.2)$ & $-0.2(-0.4$ to 0.1$)$ & \\
\hline Sitagliptin 100 mg q.d. & 60 & $2.4(0.9)$ & $2.6(1.0)$ & $0.2(-0.0$ to 0.3$)$ & $0.3(0.0 \text { to } 0.6)^{*}$ \\
\hline Sitagliptin 200 mg q.d. & 61 & $2.3(0.8)$ & $2.5(0.9)$ & $0.2(0.0$ to 0.4$)$ & $0.4(0.1 \text { to } 0.7)^{* *}$ \\
\hline \multicolumn{6}{|c|}{ 3-h post-meal glucose AUC $\left(\mathrm{mmol} \cdot \mathrm{h} \cdot \mathrm{l}^{-1}\right)$} \\
\hline Placebo & 27 & $42.0(9.4)$ & $43.4(12.9)$ & $1.1(-2.4$ to 4.5$)$ & \\
\hline Sitagliptin 100 mg q.d. & 63 & $41.3(10.7)$ & $36.2(11.3)$ & $-5.7(-7.9$ to -3.4$)$ & $-6.7(-10.7 \text { to }-2.7)^{* * *}$ \\
\hline Sitagliptin $200 \mathrm{mg}$ q.d. & 61 & $43.8(10.6)$ & $36.9(10.6)$ & $-6.6(-8.9$ to -4.3$)$ & $-7.6(-11.7 \text { to }-3.6)^{* * *}$ \\
\hline \multicolumn{6}{|c|}{ 3-h post-meal insulin AUC $\left(\mathrm{pmol} \cdot \mathrm{h} \cdot \mathrm{l}^{-1}\right)$} \\
\hline Placebo & 27 & $1,213.8(1345.2)$ & $1,000.2(1123.2)$ & $-141.6(-289.8$ to 6.0$)$ & \\
\hline Sitagliptin 100 mg q.d. & 54 & $844.8(506.4)$ & $925.8(604.2)$ & $72.6(-31.8$ to 177.0$)$ & $214.2(38.4 \text { to } 390.6)^{*}$ \\
\hline Sitagliptin 200 mg q.d. & 55 & $828.0(386.4)$ & $826.8(394.8)$ & $-15.6(-116.4$ to 84.6$)$ & $126.0(-51.0$ to 303.0$)$ \\
\hline \multicolumn{6}{|c|}{ 3-h post-meal C-peptide AUC $\left(\mathrm{nmol} \cdot \mathrm{h} \cdot \mathrm{l}^{-1}\right)$} \\
\hline Placebo & 27 & $6.5(3.2)$ & $6.1(3.0)$ & $-0.4(-0.9,0.2)$ & \\
\hline Sitagliptin 100 mg q.d. & 60 & $5.9(2.0)$ & $6.5(2.4)$ & $0.8(0.1$ to 0.9$)$ & $0.9(0.2 \text { to } 1.5)^{*}$ \\
\hline Sitagliptin 200 mg q.d. & 62 & $5.8(2.0)$ & $6.4(2.2)$ & $0.8(0.1$ to 0.9$)$ & $0.9(0.2 \text { to } 1.5)^{*}$ \\
\hline \multicolumn{6}{|c|}{ 3-h post-meal insulin:glucose AUC ratio } \\
\hline Placebo & 27 & $0.30(0.37)$ & $0.26(0.37)$ & $-0.03(-0.08,0.01)$ & \\
\hline Sitagliptin 100 mg q.d. & 54 & $0.21(0.16)$ & $0.27(0.21)$ & $0.06(0.03$ to 0.09$)$ & $0.09(0.04 \text { to } 0.15)^{* * *}$ \\
\hline Sitagliptin $200 \mathrm{mg}$ q.d. & 54 & $0.19(0.11)$ & $0.23(0.15)$ & $0.05(0.02$ to 0.08$)$ & $0.08(0.03 \text { to } 0.13)^{* *}$ \\
\hline
\end{tabular}

*** $p \leq 0.001 ; * * p \leq 0.01 ;{ }^{*} p<0.05 ;{ }^{\text {a }}$ Meal tolerance test was performed in a subset of patients $(n=150)$; To convert glucose from mmol/l to $\mathrm{mg} / \mathrm{dl}$, divide by $0.05551 ;$ q.d. once daily

meal C-peptide AUC and 3-h post-meal glucose:insulin AUC ratio (Table 1). Treatment with sitagliptin also led to an increase from baseline in 3-h post-meal insulin AUC, although this was only significant for the $100 \mathrm{mg}$ dose (Table 1).

Safety and tolerability There were no meaningful differences among the three treatment groups in the incidence of overall, serious or drug-related clinical adverse experiences, including those that led to discontinuation (Table 2). There was no statistically significant difference in the incidence of hypoglycaemia between the placebo and sitagliptin groups (Table 2). The overall incidence of gastrointestinal adverse experiences was similar across all treatment groups (Table 2). There were no statistically significant differences in the incidences of the prespecified, selected gastrointestinal adverse experiences of abdominal pain, diarrhoea, nausea and vomiting between the placebo and sitagliptin groups (Table 2). Few specific adverse experiences occurred at more than a minimally higher incidence with sitagliptin compared with placebo-these included nasopharyngitis, back pain, osteoarthritis and pain in extremities (ESM Table 2).

No laboratory adverse experiences had a notably greater incidence among the treatment groups (ESM Table 2). No clinically meaningful differences were observed in mean changes from baseline or in the frequency of elevations in alanine aminotransferase, aspartate aminotransferase or $\mathrm{CK}$ among the treatment groups. A small mean increase was observed in white blood cell count, primarily due to a small increase (5-10\%) in absolute neutrophil count for both sitagliptin doses relative to placebo. A small mean increase $(\sim 12 \mu \mathrm{mol} / \mathrm{l})$ from baseline $(\sim 330 \mu \mathrm{mol} / \mathrm{l})$ in uric acid, and a small decrease $(5-10 \%)$ in alkaline phosphatase were also observed in both sitagliptin groups relative to placebo. No adverse experiences of hyperuricaemia or gout were reported. There were no meaningful differences for other laboratory assessments.

Similarly, no meaningful differences were observed between treatment groups in mean changes in vital signs or ECG data, including QTc intervals. After 18 weeks, only small differences in change in body weight were observed in the sitagliptin groups relative to placebo (LS mean changes $[95 \% \mathrm{CI}]$ from baseline for placebo, $100 \mathrm{mg}$ and $200 \mathrm{mg}$ were $-0.7 \mathrm{~kg}[-1.3$ to -0.1$],-0.6 \mathrm{~kg}[-1.0$ to $-0.2]$ and -0.2 [ -0.7 to 0.2$]$, respectively).

\section{Discussion}

This study demonstrated that once-daily sitagliptin at doses of $100 \mathrm{mg}$ and $200 \mathrm{mg}$ provided clinically meaningful and statistically significant reductions in $\mathrm{HbA}_{1 \mathrm{c}}$ over 18 weeks compared with placebo in patients with type 2 diabetes mellitus with mild to moderate hyperglycaemia (baseline $\mathrm{HbA}_{1 \mathrm{c}} \sim 8 \%$ ). Treatment with sitagliptin also provided 

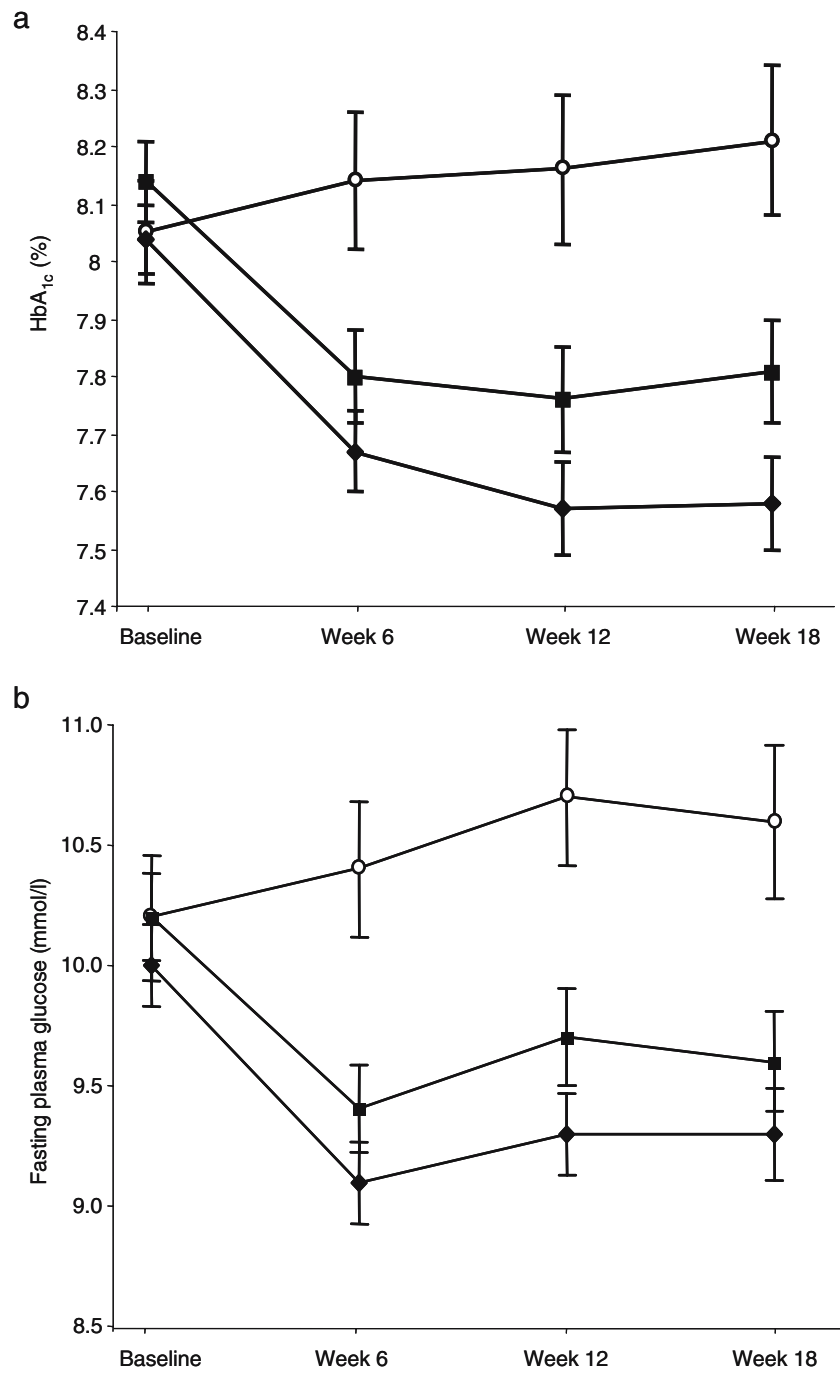

Fig. 1 Mean $\left( \pm\right.$ SEM) $\mathrm{HbA}_{1 \mathrm{c}}$ (a) and fasting plasma glucose (b) over time for placebo (open circles), once-daily sitagliptin $100 \mathrm{mg}$ (filled diamonds) and once-daily sitagliptin $200 \mathrm{mg}$ (filled squares) groups

significant improvements in the secondary glycaemic endpoints compared with placebo, including FPG, 2-h post-meal glucose and C-peptide, 3-h post-meal AUCs for glucose, C-peptide and insulin, and the 3-h post-meal insulin:glucose AUC ratio. Across all efficacy endpoints, only small differences in response between the $100 \mathrm{mg}$ and $200 \mathrm{mg}$ groups were observed - generally favouring the $100 \mathrm{mg}$ groupindicating no advantage obtained in the efficacy of $200 \mathrm{mg}$ over that of $100 \mathrm{mg}$. The reduction in post-meal glucose observed with sitagliptin treatment is consistent with enhancement of incretin levels post-meal. The reduction in FPG with sitagliptin is of interest and suggests that enhancement of active incretin concentrations in the fasting state also leads to glucose lowering. The rise in HOMA- $\beta$ suggests improved fasting insulin secretion, which probably contributed to the observed reduction in FPG. Since hepatic glucose production is an important determinant of FPG, and since higher active GLP-1 levels lower glucagon concentrations, the likely mechanism of the lowered FPG with sitagliptin is that higher insulin secretion coupled with reduced glucagon levels leads to reduced overnight hepatic glucose production.

Sitagliptin led to a significantly higher proportion of patients achieving the glycaemic goal of $\mathrm{HbA}_{1 \mathrm{c}}<7 \%$ [19] compared with placebo. The $\mathrm{HbA}_{1 \mathrm{c}}$-lowering response to sitagliptin was generally consistent across the subgroups examined. In this study, patients with a shorter duration of diabetes at baseline $\left(\leq 3.0\right.$ years) had a significantly greater $\mathrm{HbA}_{1 \mathrm{c}}$-lowering response to sitagliptin compared with those with a longer duration of diabetes, suggesting that earlier initiation of DPP-4 inhibitor therapy may provide a greater response. However, in a 24-week monotherapy trial of once-daily sitagliptin [20], this effect was not observed. In this study, severity of hyperglycaemia at baseline impacted the $\mathrm{HbA}_{1 \mathrm{c}}$-lowering response; patients with higher baseline $\mathrm{HbA}_{1 \mathrm{c}}$ had numerically greater reductions in $\mathrm{HbA}_{1 \mathrm{c}}$ compared with those with lower baseline $\mathrm{HbA}_{1 \mathrm{c}}$. The same finding was observed in the 24-week monotherapy trial with once-daily sitagliptin [20] and is a phenomenon observed with other antihyperglycaemic agents.

Loss of insulin secretion due to impaired beta cell function and mass occurs in patients with type 2 diabetes mellitus, suggesting that earlier initiation of DPP-4 inhibitor therapy may provide a greater response [21]. The improvements in HOMA- $\beta$, fasting proinsulin:insulin ratio, and 3-h post-meal insulin:glucose AUC ratio observed with sitagliptin in the present study suggests that sitagliptin improved certain parameters of beta cell function, consistent with preclinical findings as well as clinical studies with other DPP-4 inhibitors $[6-8,13,14]$. There was no significant effect of sitagliptin treatment compared with placebo on HOMA-IR, suggesting that sitagliptin may not affect peripheral insulin sensitivity.

Treatment with sitagliptin was well tolerated in this study. The incidence of hypoglycaemia in the sitagliptin groups was low and not significantly different from that seen in the placebo group. This is expected since it has been demonstrated that incretin stimulation of insulin secretion is glucose-dependent, i.e. it is not observed when glucose levels are low. Pharmacological therapy with GLP-1 has been associated with gastrointestinal adverse experiences, including nausea, vomiting and diarrhoea. Since sitagliptin increases the concentrations of active incretins, the potential for increased gastrointestinal adverse experiences with sitagliptin treatment was specifically assessed in this study. In the present study, the incidence of gastrointestinal adverse experiences was low and not significantly different from placebo. Treatment with sitagliptin had a neutral effect on body weight.

A limitation of this study was use of glycaemic rescue therapy when patients met progressively stricter glucose criteria, implemented to avoid exposure of patients to 
Table 2 Safety summary

\begin{tabular}{|c|c|c|c|}
\hline & $\begin{array}{l}\text { Placebo }(N=110), \\
n(\%)\end{array}$ & $\begin{array}{l}\text { Sitagliptin } 100 \mathrm{mg} \text { q.d. } \\
(N=205), n(\%)\end{array}$ & $\begin{array}{l}\text { Sitagliptin } 200 \mathrm{mg} \text { q.d. } \\
(N=206), n(\%)\end{array}$ \\
\hline All clinical adverse experiences & $57(51.8)$ & $102(49.8)$ & $92(44.7)$ \\
\hline Drug-related clinical adverse experiences ${ }^{\mathrm{a}}$ & $19(17.3)$ & $21(10.2)$ & $17(8.3)$ \\
\hline Serious adverse experiences & $3(2.7)$ & $8(3.9)$ & $4(1.9)$ \\
\hline Drug-related serious adverse experiences & 0 & 0 & 0 \\
\hline Discontinuations due to adverse experiences & $4(3.6)$ & $5(2.4)^{\mathrm{b}}$ & 0 \\
\hline Discontinuations due to drug-related adverse experiences & $3(2.7)$ & $1(0.5)$ & 0 \\
\hline Discontinuations due to serious adverse experiences & 0 & $3(1.5)$ & 0 \\
\hline Discontinuations due to drug-related serious adverse experiences & 0 & 0 & 0 \\
\hline Hypoglycaemia & 0 & $3(1.5)$ & $2(1.0)$ \\
\hline Overall gastrointestinal adverse experiences ${ }^{c}$ & $16(14.5)$ & $25(12.2)$ & $19(9.2)$ \\
\hline \multicolumn{4}{|l|}{ Prespecified selected gastrointestinal adverse experiences ${ }^{\mathrm{c}}$} \\
\hline Abdominal pain & $3(2.7)$ & $4(2.0)$ & $3(1.5)$ \\
\hline Diarrhoea & $4(3.6)$ & $8(3.9)$ & $2(1.0)$ \\
\hline Nausea & 0 & $2(1.0)$ & $3(1.5)$ \\
\hline Vomiting & $1(0.9)$ & 0 & $1(0.5)$ \\
\hline
\end{tabular}

${ }^{a}$ Determined by the investigator to be possibly, probably or definitely drug-related

${ }^{\mathrm{b}}$ Includes one patient who discontinued during the initial placebo-controlled phase, and four patients who discontinued after completing this phase because of adverse experiences that had an onset during the placebo-controlled phase

${ }^{\mathrm{c}}$ Excludes events that occurred after initiation of glycaemic rescue therapy with metformin q.d. once daily

prolonged hyperglycaemia. Only efficacy data prior to rescue were used in the analysis; however, the use of rescue therapy could impact the estimation of glycaemic efficacy, especially as more patients in the placebo group were rescued. Nonetheless, since $<20 \%$ of placebo patients required rescue, this is unlikely to be a source of substantial bias in estimation of efficacy.

In this study, there was a slight numerical benefit of sitagliptin $100 \mathrm{mg}$ compared with $200 \mathrm{mg}$. In another monotherapy trial of once-daily sitagliptin that was similarly designed (except for a 24-week double-blind period) [20], there was a slight numerical benefit of $200 \mathrm{mg}$ compared with $100 \mathrm{mg}$. Taken together, these data do not demonstrate a consistent benefit of sitagliptin $200 \mathrm{mg}$ over $100 \mathrm{mg}$.

In conclusion, this 18 -week study in patients with type 2 diabetes mellitus and inadequate glycaemic control on diet and exercise demonstrated that once-daily sitagliptin, at doses of $100 \mathrm{mg}$ and $200 \mathrm{mg}$, provided statistically significant and clinically important reductions in $\mathrm{HbA}_{1 \mathrm{c}}$, FPG and 2-h post-meal glucose, as well as significant improvements in indices of insulin secretion and beta cell function, including HOMA- $\beta$ and fasting proinsulin:insulin ratio. Treatment with sitagliptin was well tolerated and was associated with a low rate of hypoglycaemia, which was not significantly different from placebo, as well as a neutral effect on body weight.

Acknowledgements Funding for this study was provided by Merck Research Laboratories. The authors wish to thank A. G. Meehan (Merck Research Laboratories) for his contribution in writing this manuscript.
Duality of interest L. Xu, C. Caria, D. Williams-Herman and $\mathrm{H}$. Khatami are employees of Merck Research Laboratories.

\section{References}

1. Kim D, Wang L, Beconi $\mathrm{M}$ et al (2005) (2R)-4-oxo-4-[3(trifluoromethyl)-5,6-dihydro[1,2,4]triazolo[4,3-a]pyrazin-7(8H)yl]-1-(2,4,5-trifluorophenyl)butan-2-amine: a potent, orally active dipeptidyl peptidase IV inhibitor for the treatment of type 2 diabetes. J Med Chem 48:141-151

2. Holst JJ, Gromada J (2004) Role of incretin hormones in the regulation of insulin secretion in diabetic and nondiabetic humans. Am J Physiol Endocrinol Metab 287:E199-E206

3. Mentlein R, Gallwitz B, Schmidt WE (1993) Dipeptidylpeptidase IV hydrolyses gastric inhibitory polypeptide, glucagon-like peptide-1(7-36)amide, peptide histidine methionine and is responsible for their degradation in human serum. Eur $\mathrm{J}$ Biochem 214:829-835

4. Deacon CF, Johnsen AH, Holst JJ (1995) Degradation of glucagon-like peptide-1 by human plasma in vitro yields an $\mathrm{N}$ terminally truncated peptide that is a major endogenous metabolite in vivo. J Clin Endocrinol Metab 80:952-957

5. Herman G, Zhao P-L, Dietrich B et al (2004) The DP-IV inhibitor MK-0431 enhances active GLP-1 and reduces glucose following an OGTT in type 2 diabetics. Diabetes 53(Suppl 2):A82, (Abstract)

6. Reimer MK, Holst JJ, Ahren B (2002) Long-term inhibition of dipeptidyl peptidase IV improves glucose tolerance and preserves islet function in mice. Eur J Endocrinol 146:717-727

7. Pospisilik JA, Stafford SG, Demuth HU, Brownsey R, Parkhouse W, Finegood DT (2002) Long-term treatment with the dipeptidyl peptidase IV inhibitor P32/98 causes sustained improvements in glucose tolerance, insulin sensitivity, hyperinsulinemia, and betacell glucose responsiveness in VDF (fa/fa) Zucker rats. Diabetes 51:943-950 
8. Pospisilik JA, Martin J, Doty T et al (2003) Dipeptidyl peptidase IV inhibitor treatment stimulates beta-cell survival and islet neogenesis in streptozotocin-induced diabetic rats. Diabetes 52:741-750

9. Mu J, Woods J, Zhou Y-P et al (2006) Chronic inhibition of dipeptidyl peptidase-4 with a sitagliptin analog preserves pancreatic $\beta$-cell mass and function in a rodent model of type 2 diabetes. Diabetes 55:1695-1704

10. Paris M, Tourrel-Cuzin C, Plachot C, Ktorza A (2004) Review: pancreatic beta-cell neogenesis revisited. Exp Diabesity Res 5: $111-121$

11. Buse JB, Henry RR, Han J et al (2004) Effects of exenatide (exendin-4) on glycemic control over 30 weeks in sulfonylureatreated patients with type 2 diabetes. Diabetes Care 27:2628-2635

12. DeFronzo RA, Ratner RE, Han J, Kim DD, Fineman MS, Baron AD (2005) Effects of exenatide (exendin-4) on glycemic control and weight over 30 weeks in metformin-treated patients with type 2 diabetes. Diabetes Care 28:1092-1100

13. Mari A, Sallas WM, He YL et al (2005) Vildagliptin, a dipeptidyl peptidase-IV inhibitor, improves model-assessed beta-cell function in patients with type 2 diabetes. J Clin Endocrinol Metab 90:4888-4894

14. Ahren B, Pacini G, Foley JE, Schweizer A (2005) Improved mealrelated beta-cell function and insulin sensitivity by the dipeptidyl
peptidase-IV inhibitor vildagliptin in metformin-treated patients with type 2 diabetes over 1 year. Diabetes Care 28:1936-1940

15. Scott R, Herman GA, Zhao PL, Chen X, Wu M, Stein PP (2005) Twelve-week efficacy and tolerability of MK-0431, a dipeptidyl peptidase IV (DPP-IV) inhibitor, in the treatment of type 2 diabetes. Diabetes 54(Suppl 1):A10, (Abstract)

16. Herman GA, Hanefeld M, Wu M, Chen X, Zhao PL, Stein PP (2005) Effect of MK-0431, dipeptidyl peptidase IV (DPP-IV) inhibitor, on glycemic control after 12 weeks in patients with type 2 diabetes. Diabetes 54:A134, (Abstract)

17. Roche Diagnostics, Indianapolis, Indiana, USA. Elecsys insulin package insert

18. American Laboratory Products Co., Winham, New Hampshire, USA (1997) Mercodia proinsulin ELISA package insert

19. American Diabetes Association (2003) Standards of medical care for patients with diabetes mellitus. Diabetes Care 26(Suppl 1):S33-S50

20. Aschner P, Kipnes M, Lunceford M et al (2006) Sitagliptin monotherapy improved glycemic control in the fasting and postprandial states and beta-cell function after 24 weeks in patients with type 2 diabetes (T2DM). Diabetes 55(Suppl 1):A462

21. Berman RN, Finegood DT, Kahn SE (2002) The evolution of $\beta$-cell dysfunction and insulin resistance in type 2 diabetes. Eur J Clin Invest 32(Suppl 3):35-45 